\title{
Learning by Making. Long-term collaborations and socially productive outcomes
}

\author{
Richard Burnham, Louise Wallis \\ University of Tasmania, Australia \\ School of Architecture \& Design \\ Richard.Burnham@utas.edu.au | Louise.Wallis@utas.edu.au
}

\begin{abstract}
The Learning-by-Making (LBM) program at the University of Tasmania has 20 years experience in collaborative, community-based "live" studios. Academics involved in the program have intuitively understood that a learning environment integrated with the public realm, and based in a constructed reality affords students an immersive understanding of the design process. More recently the program has shifted its focus from stand-alone, client-responsive projects to a long-term, design-led research agenda. Individual projects - including micro-dwellings, scout huts, an exhibition stand and a mobile playground - are seen as steps in the evolution of an innovative building system that harnesses the creative and socially productive potentials of digital fabrication. The benefits of this shift for academics and clients are clear. For academics, research and teaching activities can be mutually supportive, while clients benefit from a design/fabricate/assemble process that has been tested, analysed, applied and incrementally improved. The primary focus of this paper will however attempt to identify the educational impact on participating students, and will do so using the analytical lens of a relevant educational theory called threshold concepts'. The theory suggests that students can overcome barriers to learning when specific criteria or "dimensions" are present.

The results of this analysis indicate that in this environment learning can be transformative, resulting in irreversible conceptual links between design idea, fabrication and practice. The conceptual space of the project is bounded by the research objective, budget, technology and client requirements, and integrative in that they inevitably involve decisions on materials, structures, habitation patterns and climate control. The learning is discursive as students are required to articulate their opinions on design decisions, both within the student group and with community collaborators. The primary data sources for this investigation have been students' reflective journals, combined with teacher observations.
\end{abstract}

Keywords: digital fabrication, design-build, live projects, experiential learning, architectural education.

\section{To cite this article:}

Burham, R., Wallis, L. (2017). Learning by Making. Long-term collaborations and socially productive outcomes. The Journal of Public Space, 2(3), Special Issue, 73-84, DOI:

10.5204/jps.v2i3.116

This article has been peer-reviewed and accepted for publication in The Journal of Public Space. Please see the Editorial Policies under the 'About' section of the journal website for further information. International License https://creativecommons.org/licenses/by-nc/4.0/ 
Design is a troublesome concept to teach. It is varied, complex, difficult to capture in cognitive dimensions' and is not readily learnt through reading or instruction. Design represents a devised solution to what is often an ill-defined problem and requires students to hold the domains of idea and construction simultaneously, in a dynamic balance.

Learning-by-making (LBM) studios, inspired by experiential learning, ${ }^{2}$ provide an environment where students are encouraged to strengthen conceptual links between idea and fabrication, and to take collective responsibility for designing, prototyping and realising a "live" design project. The 120 completed projects include stage sets, exhibition stands, bus stops and bush installations. The experience is experimental in nature, providing impartial and tangible feedback to students. Students are exposed to reality, as opposed to a representation of reality, and they cannot indefinitely resist the integration of construction into a design response. There is no space for "bluffing gravity." LBM has become an invaluable asset to the school in terms of community engagement and is a highly visible manifestation of the school's professional and educational values.

Recently the program has expanded its focus from stand-alone, client-responsive projects to a long-term, design-led research agenda based on long-term collaborations with community partners. Individual projects are seen as steps in the evolution of an innovative building system that harnesses the creative and socially productive potentials of digital fabrication. The research hypothesis proposes that digital fabrication can strengthen the conceptual and physical links between design and construction, and that the precision and reliability of digital fabrication can be harnessed for socially productive outcomes. The products prototyped by LBM studios over the past six years - including furniture, a teardrop camper, a skate ramp, micro-dwellings and a scout hut (see figure I) - are assembled by unemployed youth in a formal construction-training environment run by Youth Futures Inc. (YFI), a registered training organisation. LBM students prototype the designs (with close collaboration from YFI) and the "kit of parts" is handed over for serial manufacture. The process is driven by a customised plugin to SketchUp, called "SuperSlob," developed by the school to a brief of accessibility, transparency, reliability and predictability. The process facilitates three-dimensional arrangements of sheet-based CNCcut components (primarily plywood) connected with a limited suite of jointing patterns, and assembled with a limited toolset of rubber mallet and screws. ${ }^{3}$

The benefits for academics of this shift is that research and teaching activities can be mutually supportive, while clients benefit from a design/fabricate/assemble process that has been tested, analysed, applied and incrementally improved. For example The Castle - an extendable micro-dwelling intended for youth at risk of homelessness - has undergone several iterations before Housing Tasmania commissioned YFI and the school to design and deliver 8 Castles to their own requirements. While it has been possible to form a generalised opinion as to the educational benefits of this evolved research-based LBM

\footnotetext{
' Bryan Lawson, How Designers Think: The Design Process Demystified, 3rd ed. (Oxford: Elsevier/Architectural, 1997), 305.

2 David Kolb, Experiential Learning: Experience as the Source of Learning and Development (Englewood Cliffs, NJ: Prentice Hall, 1984).

${ }^{3}$ Ryan Tubby, Richard Burnham, and Robin Green, "SuperSlob: The Development of a Parametric Component Jointing Regime For Standard Sheet Materials," Building on Knowledge, Theory and Practice: Proceedings of the 46th Annual Conference of the Architectural Science Association, ed. Henry Skates (Southport, Queensland: Griffith University, 20I2), I-2.
} 
model, it is the purpose of this paper to begin a more objective evaluation of its transformative potential for students.
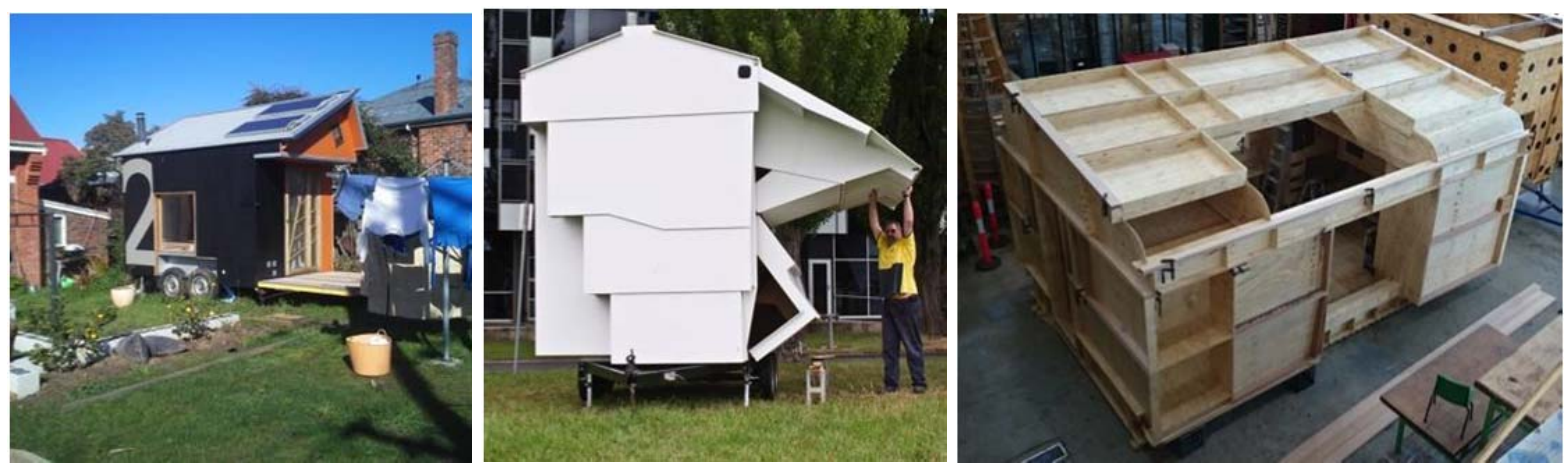

Figure I. A selection of projects from the LBM digital fabrication research activity (left to right): The Castle2 in backyard setting; The Castle5 - unfolding; Scout-hut prototype).

\section{Methodology}

Literature related to "live" design-build studios is often criticised for inadequate rigour and a lack of connection to existing educational theory, instead focusing on the built outcome and a general impression of student satisfaction. This pattern, observed more broadly within architectural education, has caused a few to speculate whether those involved in the "doing" are more adept and motivated by practice and tacit knowledge rather than its relationship to learning theories. ${ }^{456}$

Threshold concepts ${ }^{7}$ was chosen as an appropriate framework to evaluate learning as it provides a way for educators to identify barriers in student understanding and subsequently develop methods to overcome them ${ }^{89}$ (the framework also provides an alternative to documenting the teaching approach, which has been explored in previous LBM articles ${ }^{10}$ II

\footnotetext{
${ }^{4}$ Bob Fowles, "Design-Build Projects in Architectural Education,” Design Studies 5, n. I (1984): 7-I4; Helena Webster, "Facilitating Critically Reflective Learning: Excavating the Role of the Design Tutor in Architectural Education," Art, Design \& Communication in Higher Education 2, n. 3 (2004): I0 I- I I ; Lawson, How Designers Think, 307.

${ }^{5}$ Helena Webster, "Facilitating critically reflective learning: excavating the role of the design tutor in architectural education." Art, Design \& Communication in Higher Education, 2 (2004): I0I-I I I.

${ }^{6}$ Bryan Lawson, How designers think: the design process demystified: 307.

${ }^{7}$ Meyer and Land, "Threshold Concepts," 3-I8.

${ }^{8}$ Glynis Cousin, “An Introduction to Threshold Concepts,” Planet 17 (December, 2006), accessed October 6, 2014, http://www.gees.ac.uk/planet/p/7/gc.pdf; Jos Boys, "Learning Spaces From an Educationalist Perspective," in Towards Creative Learning Spaces: Re-thinking Architecture of Post-Compulsory Education, ed. Jos Boys (London: Routledge, 20I I), 37-50.

9 Jos Boys, "Learning spaces from an educationalist perspective," in Towards Creative Learning Spaces: Rethinking Architecture of Post-Compulsory Education, ed. J. Boys (London: Routledge, 20 I I), 37-50.

${ }^{10}$ Richard Burnham and Louise Wallis, "The Castle: A Long-term Community Partnership," in Live Projects Designing with People, ed. Melanie Dodd, Fiona Harrisson, and Esther Charlesworth (Melbourne: RMIT University Press, 2012), I86-191; Richard Burnham, Louise Wallis, lan Clayton, and Robin Green, "University of Tasmania: The Castle," in Design Build Studio, ed. William Carpenter (Decatur, Georgia: Lightroom, 20I I), 38I-39; Louise Wallis, “Building the Studio Environment,” in Design Studio Pedagogy: Horizons for the Future, ed. Ashraf M. Salama and Nicholas Wilkinson (Gateshead: Urban International Press, 2007), 20I - 218.

" Richard Burnham et al. "University of Tasmania: The Castle," in Design Build Studio, ed. William Carpenter (Decatur, Georgia: Lightroom, 20II), 38I-39.
} 
$\left.{ }^{12}\right)$. A threshold concept is understood to be a concept with which students may become stuck and experience difficulties until, "a new and previously inaccessible way of thinking about something" is achieved. ${ }^{13}$ A threshold concept represents a "portal" that students need to travel through in order to transform their thinking and enable progress in further studies. The characteristics of the research-based LBM studios will be analysed in relation to the most common characteristics attributed to threshold concepts: transformative, integrative, bounded, discursive and troublesome. ${ }^{14}$

The primary source of data comes from the design reports that LBM students are required to submit, critically reflecting on the learning outcomes; communication; collaboration; making and speculation. The design reports (selected from seven LBM studios between 2013 and $2015^{15}$ ) provide evidence as to whether students are making conceptual links between design, fabrication, assembly and practice. We have also drawn on the authors' observations from LBM studios, as well as stakeholders' observations. ${ }^{16}$

\section{Transformative}

The transformative characteristic of a threshold concept reflects the change that occurs when a student understands a new way of thinking and/or practicing the discipline subject matter. ${ }^{17}$ The fundamental shift in understanding occurs when an idea is translated into reality. LBM studios highlight the links between idea and the implications for its subsequent fabrication, including the properties of materials, connections, component specification, fabrication processes, tooling and the patterns of habitation. Students are encouraged to use physical models instead of drawings, reinforcing skills in three-dimensional thinking and reducing the abstraction that can occur between paper-based design and object. SketchUp software was selected because object making on this platform is conceptually transparent, accessible and SketchUp can support every step of the process: conceptual design, detailed resolution, CNC file preparation, documentation and animated assembly instructions.

Seeing the image on the screen become a physical reality and seeing the stack of plywood become a habitable structure are a magical transformations that should never be underestimated.

The fact that every single detail of this small object had to be resolved reveals the delusion of the oversimplified design processes in other studio assignments. We understood that the other half of the project is to see how it can be pushed to I:I scale with real material. (Third year student B, 20I3)

\footnotetext{
${ }^{12}$ Louise Wallis, "Building the Studio Environment," in Design Studio Pedagogy: Horizons for the Future, ed. Ashraf M. Salama and Nicholas Wilkinson (Gateshead: Urban International Press, 2007), 201- 218.

${ }^{13}$ Erik Meyer and Ray Land, “Threshold Concepts,”, 2006: 3.

${ }^{14}$ Ibid, 7-8.

${ }^{15}$ University of Tasmania, Ethics Reference Number: H0OI4468.

${ }^{16}$ John Creswell and Vicki Plano Clark, Designing and Conducting Mixed Methods Research (Los Angeles: Sage, 20II).

${ }^{17}$ Erik Meyer and Ray Land, "Threshold Concepts," 7.
} 

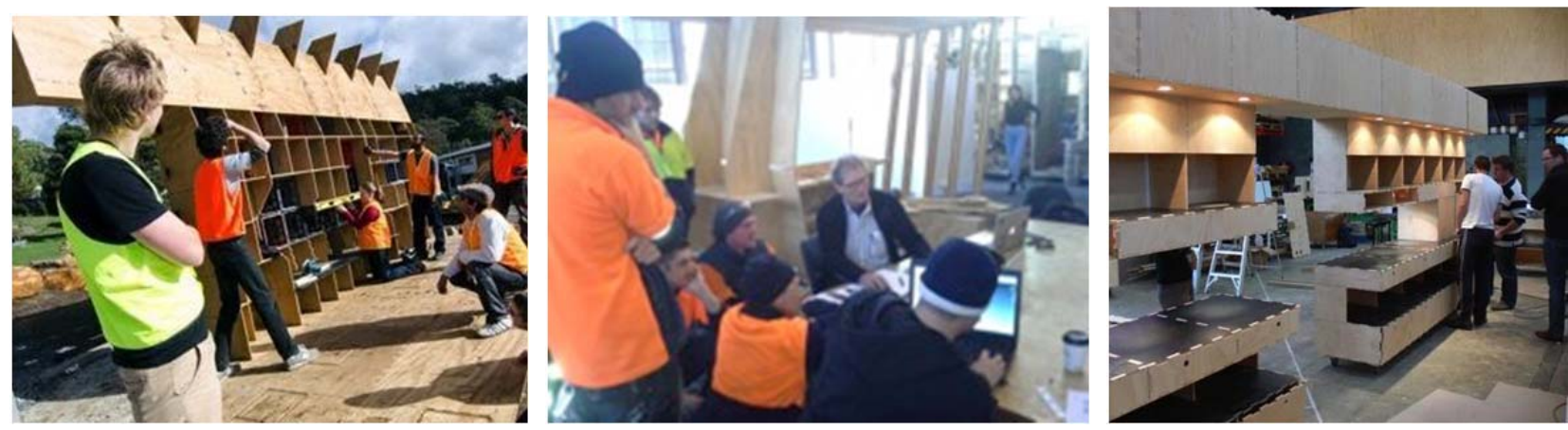

Figure 2. Left to right: Outdoor Learning Space assembly; collaboration with Youth Futures trainees; Design-Made-Trade Exhibition Stand.

We believe that transformations in learning may be more powerful and enduring if they are achieved collaboratively or through students taking a role of responsibility. The structure of an LBM studio actively encourages collaborative decision-making, initially in rapid cycles of model making in small groups, followed by the coalescing of ideas with the studio as a whole. The student group is slowly given the opportunity to take responsibility for the design evolution, goal setting and ultimately the delivery of the project.

I believe that my skills in team leadership increased dramatically through having to sometimes take charge to get a task completed (Third year student C, 20I3).

Working alongside clients and their representative - including homeless youth, school students, work-experience trainees, school students and teachers - design students are exposed to a diversity of world-views, providing enriching and sometimes confronting experiences. Emotional engagement with a design project that has a socially productive outcome may reinforce the learning. Students involved in The Castle (2008-) have regular contact with YFI trainees and supervisors who provide feedback on proposed assembly procedures and detailing. The pop-up Skate ramp (2016) involved discussions with professional skaters and graffiti artists. Samuel Mockbee, the Director of Rural Studio suggests: "What we should do is go into their world and understand it. They go out there with pre-conceived ideas, only to discover that they gonna learn something from these people."18

Land and Meyer ${ }^{19}$ suggest that the transformative characteristic of a threshold concept is related to whether the learning is irreversible, enduring and difficult to "unlearn." The core knowledge needs to remain intact and the student unlikely to return to previous modes of thinking. Students regularly refer to the learning that comes as a consequence of making a mistake and the subsequent redefining of a problem or solution. For example one student titled their Design Report, "I0 Lessons Learnt by Making Decisions and Mistakes as a Group” (Third year student F, 20 I4). Learning from mistakes may be one of the most effective types of feedback that a student can receive.

\footnotetext{
${ }^{18}$ Citizen Architect: Samuel Mockbee \& the Spirit of the Rural Studio, directed by Sam Wainwright Douglas (Big Beard Films, 2010), accessed August 10, 2014, http://citizenarchitectfilm.com/.

19 Meyer and Land, "Threshold Concepts," 7.
} 
An important attitude that I personally still need to improve is instead of being afraid of errors, I should look for errors, embrace their existence and tackle them. (Second year student $\mathrm{H}, 20 \mathrm{I5})$.

\section{Integrative}

Threshold concepts may also involve integrating or synthesising knowledge that was previously viewed to be unrelated. ${ }^{20}$ In contrast with reductive design curriculums where design, building technology, theory and professional conduct are taught separately, LBM students are exposed to many interrelated activities that comprise design practice; including researching and specifying appliances and components, consulting with clients and suppliers and considering the implications of assembly sequencing. As well as mimicking the realities of design practice there are often opportunities for component stress testing (supervised by an engineer) to be integrated into the evolution of the design.
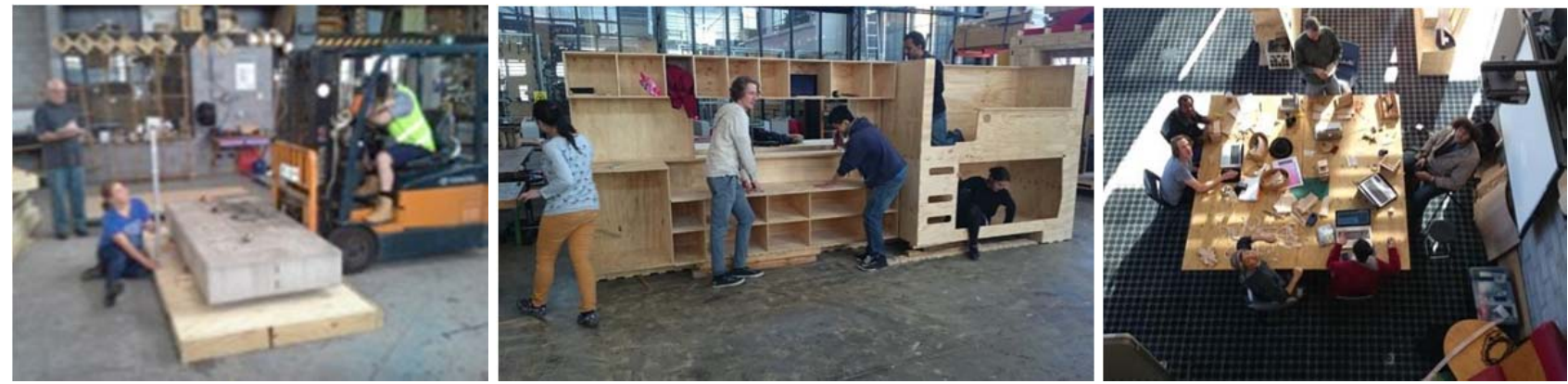

Figure 3. Left to right: Wall panel stress testing; Scout hut prototyping; Collaborative design environment.

The Castle (2008-) and the Teardrop Caravan (2014-) require an integrated consideration of all aspects of a habitable environment: servicing, structure, openings, privacy as well as notions of home and identity. The Playbox (2014), commissioned by the Tasmanian Catholic Education Office, is based around an educational theory called "Loose Parts,"21 and required integration of Australian Standards for small trailer design, storage of an optimum mix of found objects and use as a small playground (see figure 8).
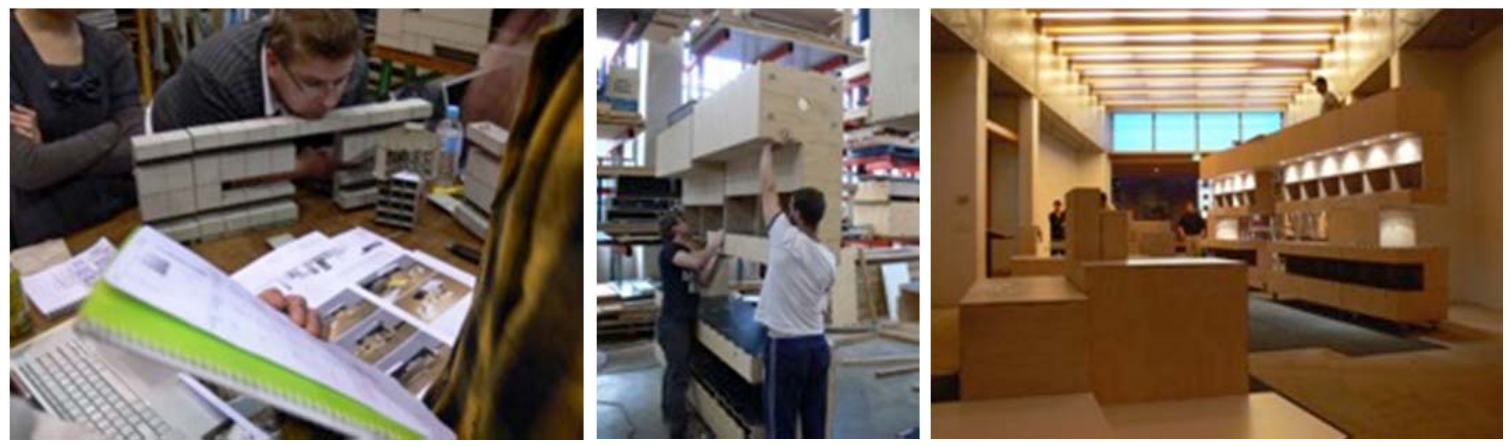

Figure 4. Design Made Trade Exhibition stand. Left to right: multi-media design; assembly; installation.

\footnotetext{
${ }^{20}$ Ibid.

${ }^{21}$ Simon Nicholson, "How Not to Cheat Children: The Theory of Loose Parts", Landscape Architecture 62 (197I).
}

78 | The Journal of Public Space, 2(3), 2017 | Special Issue | ISSN 2206-9658

(C) Queensland University of Technology 
The student groups are required to synthesise their ideas into a single buildable outcome. Ownership by the whole studio is seen as being important in maintaining collaborative energy, responsibility and teamwork. As stated, ideas are gradually coalesced, edited, integrated and distilled until a single digital or physical model embodies the aspirations of the studio.

When I look at the finished object I can see that my idea had been included, but in a way I hadn't thought of. (Second year student E, 20I3).

One effective and active model for design collaboration centres around a projected image of the digital model. One student is responsible for manipulating, adding to and amending the model, based on the suggestions of the rest of the group. Collaboration between master's and undergraduate students is also encouraged, in a context where undergraduate students apply and test research knowledge provided by master's students.

\section{Bounded}

The bounded ${ }^{22}$ characteristic of threshold concept refers to the setting of appropriate parameters for a given project. The "external boundaries" of an LBM project - brief and budget - and the "internal boundaries" - research, technology and project timeframe serve a limiting purpose and create an appropriate conceptual space for the learning to occur.

The extended timeframe and multiple project experience of the current LBM research-led regime have allowed the parameters of the SuperSlob digital fabrication process and the associated construction system to slowly evolve into a defined and refined process. The basic boundaries of the system are clear to the students: Sketch-up SuperSlob, $12 \mathrm{~mm}$ plywood, CNC cutting, mallet and screws. Preferred settings for materials, tooling and assembly (tolerance between components, span tables and screw profile) have all been established through trial and error. Even the use of a rubber mallet has generated some guidelines associated with choice of mallet weight, the order and direction of use and the need to listen and respond to the tone of the impact. A more general and enduring design aspiration is that every component should be "useful" to the inhabitants, either in terms of enclosing space or as furniture (i.e., eliminating components whose sole role is structural). Having established these basic but critical settings, subsequent students have increased opportunities for creating new knowledge, including current investigations into thermal performance, efficient "nesting" of components on plywood sheets, "kerfing" (using perforation and scoring patterns to achieve bending) and animated assembly instructions. The limited toolset allows all students to participate on equal terms, whereas many traditional skills are problematic for those who have not had prior exposure. The boundaries necessary to pursue a research agenda may however appear excessively restrictive to students who believe that there are other ways of fulfilling the project brief (e.g., "why can't we use studs rather than sheets?").

Several projects, most notably The Castle, have involved multiple iterations of the same brief - mobile, autonomous crisis accommodation for a single young person - which has

\footnotetext{
${ }^{22}$ Meyer and Land, "Threshold Concepts," 8.
} 
resulted in students being able to make an evidence-based judgement on, for example, how much headroom is required for sitting, reading in a sleeping loft, or the ideal layout for a compact kitchen.

The bounded characteristic assists students to familiarise themselves with the boundaries of the discipline and practice. Students are encouraged to initiate communication with local authorities and to ensure compliance with planning and building regulations, structural adequacy and standards.

After extending our knowledge on the specifications and regulations we had a more informed and realistic approach that we hope affected the design process for the better. (First year domestic student F, 20I3).

In all LBM studios students are exposed to varying degrees of risk and are expected to become responsible for risk management (including appropriate documentation).

According to Harriss ${ }^{23}$ exposure to and management of risk can be an important dimension of learning.

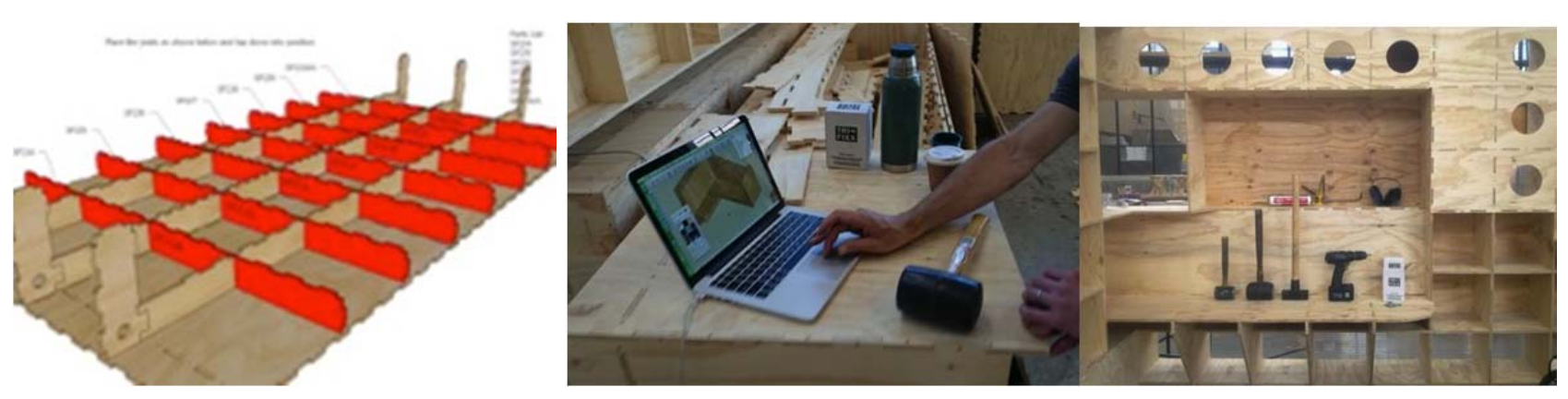

Figure 5. Left to right: animated assembly instructions; digital and manual tools; the Superslob toolset.

\section{Discursive}

Land and Meyer $^{24}$ make reference to the role that extending discipline language can play in mastering a threshold concept. Appropriate and effective communication is explicitly encouraged within the LBM studio, both within the student group and with clients and community partners. Design preferences can be passionately argued within the student group but opinions must be respectful and justified using discipline language (e.g., "firmness, commodity and delight") or documented evidence (e.g., sketch, model, manufacturers specification). Students' written reflections often focus on the dynamics within the studio, commenting that irrational or defensive "ownership" of relevant information or ideas had the most destructive impact on project progress.

... students were guided rather than directed, leaving the responsibility up to us, simulating a real-world studio environment. At times this was an exasperating experience, when stubborn personalities cling to irrational ideologies that restrict

\footnotetext{
${ }^{23}$ Harriet Harriss, ed., Architecture Live Projects: Oxford School of Architecture 2010-20I 2 (Oxford: Oxford Brookes University, 20I2).

${ }^{24}$ Meyer and Land, "Threshold Concepts," 14.
} 
progress. However, as the semester progressed it became apparent to me that rather than the physical model, managing group politics was the most valuable learning outcome. (Third year domestic student M, 20I4)

We were inevitably headed for a crash at some point. But when it came, it actually clarified things. It was such a relief to finally hear the real reasons behind some of these ideas and critique them honestly. Sure there were nearly some deaths, but the afterglow was certainly worth it. (Third year domestic student $Y, 20 I 4$ )

There are certain discursive characteristics that emerge when students and long-term clients are invested in the intricacies of a particular way of doing things. Over the years the SuperSlob system has evolved a language of its own, where terminology is shared and owned by the participants in the project. The terms "slobbing" (a portmanteau of "slot" and "tab"), "mouse-ear" (the radius applied to an internal corner) and "mallet whispering" (reflective skill of using the rubber mallet) become common usage.
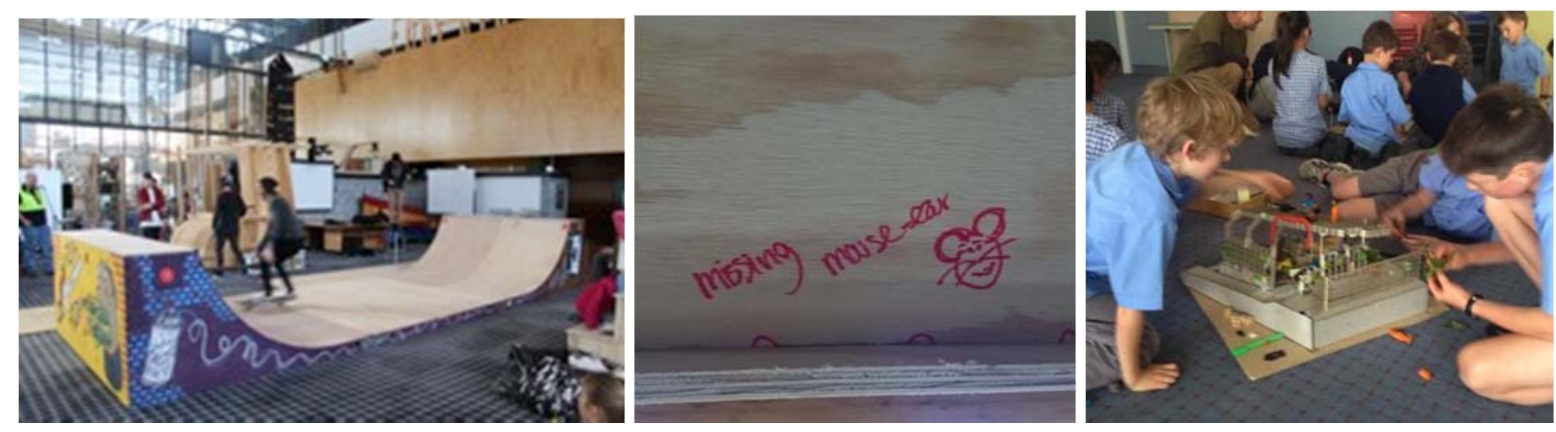

Figure 6. Left to right: Pop-up skate-ramp; identifying 'missing mouse-ear'; design workshop with primary school students.

Listening and observing are stressed as primary skills for designers and students are encouraged to be conscious of the verbal, spatial or graphic vocabularies their community collaborators use.

The most notable difference when comparing differences between architecture and primary school students was the choice of words when describing elements in design. The Trevallyn students were able to effectively and clearly articulate their design ideas and concepts to other primary school students and to us architecture students. (Third year domestic student C, 2013)

Physical models are promoted as the primary communication medium from concept to construction and are particularly effective because participants can gather and talk across and around the model.

The models were a great way to interact with the children, and were very successful in deriving design ideas made by the children (Third year domestic student $\mathrm{H}, 20 \mathrm{I}$ ). 
Models are capable of either a positive ambiguity or an explicit accuracy. Students are encouraged to mark-up and manually edit laser-cut models in order to discourage the perception of precision, perfection and resolution.
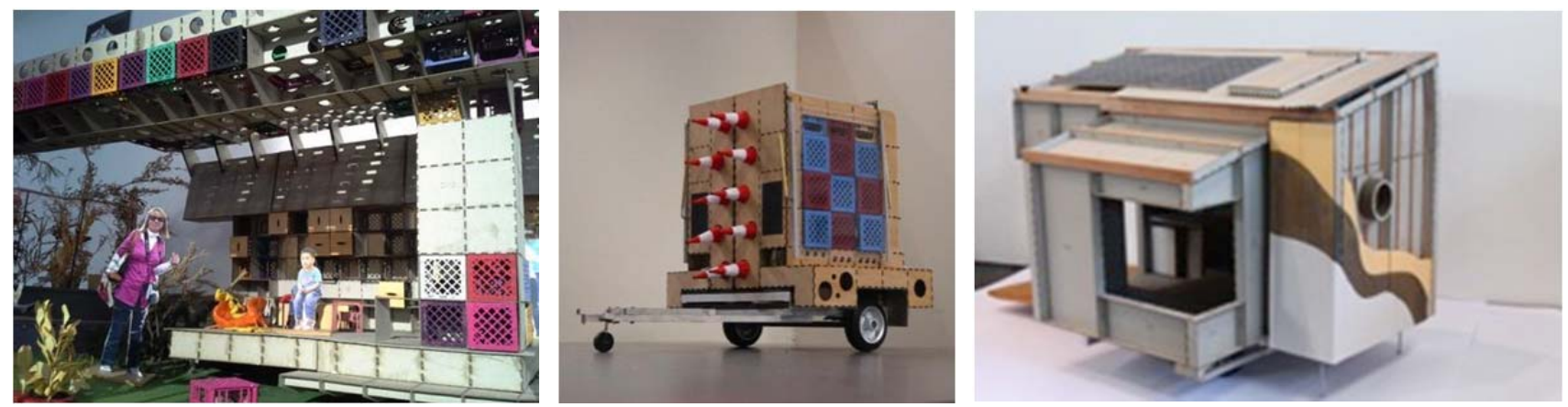

Figure 7. Left to right: Outdoor Learning Space model; Playbox model; CastleX model.

\section{Troublesome}

Troublesome knowledge $\mathrm{e}^{25}$ is characterised as being difficult to understand. Design, due to its inherent tacit and cultural characteristics, challenges many students, ${ }^{26}$ and for some the experience of an LBM studio does not alleviate their "stuckness." These students may fully participate in the studio and report a positive experience but their fundamental understanding of the design process does not appear to shift. They are unable to apply the new knowledge in subsequent studies. We observe this phenomenon in some first-year building technology students who, despite building a small timber frame shed are unable to translate that direct knowledge to documenting a timber frame building the following semester. The difficulty experienced by students to transform troublesome knowledge is well documented in threshold concept literature, after a decade of testing and debate. ${ }^{27}$ It is possible that for some "self-reflexive" learners the transformation may take time or may require consolidation. A student reflects:

At least I realise now that I enjoyed the process and learnt more than I realised at that point in time. (Third year student D, 20I4).

Earlier research has shown that master's students found LBM studios valuable as undergraduates because it helped contextualise knowledge gained later in the course, ${ }^{28}$ but found it difficult to reconcile with more complex briefs or when timber construction is no longer used. ${ }^{29}$ Samuel Mockbee believes that a "delayed response" is common for many

\footnotetext{
${ }^{25}$ David Perkins, “Constructivism and Troublesome Knowledge,” in Meyer and Land, 33-47.

${ }^{26}$ Ibid.

${ }^{27}$ Ray Land, "Toil and Trouble," in Threshold Concepts in Practice, ed. Ray Land, Jan Meyer, and Michael Flanagan (Rotterdam: Sense Publishers, 2016), II-24.

${ }^{28}$ Louise Wallis, "Learning-by-Making: Design-Build Studios at the School of Architecture at the University of Tasmania” (master's thesis, University of Tasmania, 2005), I43.

29 Ibid, 143.
} 
Rural Studio participants, that they only understand the significance of their experience many years later. ${ }^{30}$

The collaborative nature of the studios can enhance learning for some but if a student's identity within the studio group is fragile then collaboration can be troublesome; their roles and their relationships with other students may be problematic, uncomfortable or even traumatic. ${ }^{31}$ If their position in the group is put under scrutiny, either by themselves or by others, students will find other aspects of studio content - questions of practicality, creativity, and interpretation of client requirements - much more challenging. The way of finding some confidence is a recent development in threshold concepts theory. ${ }^{32}$ It would not be particularly surprising that knowledge gained from direct experience with a non-standard construction system such as SuperSlob is not readily applicable by students in later studies, but perhaps there are other attributes of a research-led "live" studio that can impact on "stuckness." Firstly, emotional engagement with a socially productive endeavour and being able to see that the research activities already have meaningful "runs on the board" may contribute to an atmosphere more conducive to learning. Secondly, when students know that they are contributing to a bigger picture, by for example, providing feedback on improvements to the performance of the software or developing animation techniques to communicate assembly procedures, the learning becomes two-way.

\section{Conclusions}

Despite difficulties in evaluating precise educational outcomes of the LBM studios the analytical lens of threshold concept has identified several attributes of the program that appear helpful in supporting students' understanding of design. Through analysis of students' reflections we believe that the most powerful transformative characteristics are as follows:

- the impact of translating idea into reality;

- having space to make mistakes and learn from them;

- being emotionally engaged with the people and the project;

- being exposed to differing world-views removed from the self-affirming environment of the design studio;

- taking collective responsibility for decisions and their outcomes;

- the integration of different types of design information ;

- awareness and enhancement of design media and discipline language.

It is important to remember that individual students in a given LBM studio appear to have been impacted by different aspects of the project, whether it might be the frustrations of group decision-making processes or the opportunity to explore the detailed design and fabrication of an operable round window.

The bounded, discursive and integrated dimensions of threshold concept have been helpful for studio coordinators in considering the scope and structure of an LBM studio. While there is a role for open-ended and speculative LBM studios the boundaries created by an on-going research agenda and long-term client relationships are generally helpful in

\footnotetext{
30" Citizen Architect."

${ }^{31}$ Glynis Cousin, "Threshold Concepts, Troublesome Knowledge and Emotional Capital: An Exploration into Learning About Others," in Meyer and Land, I34- I 47.

${ }^{32}$ Peter Felton, “On the Threshold with Students," in Land, Meyer, and Flanagan, 6.
} 
focussing student energy. Further understanding of how the bounded dimension influences learning outcomes may suggest that undergraduate LBM projects should be more tightly bounded, whereas master's LBM studios might involve more open-ended and speculative research. Despite the growing bank of knowledge in the SuperSlob system, new areas of experimentation and research regularly emerge e.g., "kerfing" where perforation and scoring patterns add "bending" to what is an intrinsically orthogonal construction system. The analysis of the design reports identifies that for some students overcoming "stuckness" may need more time and more reinforcing experiences. If we pursue this line of enquiry we need to improve the quality and quantity of the data, meaning that we can more effectively and more accurately gauge the transformative impact of the LBM studio on students. The design report is a useful starting point but it could be more effectively targeted, requiring that students make more explicit reference to the ways that they have acquired, applied and retained new knowledge. The structure of the design report could be tailored to address our current knowledge gaps. Future research will map trends occurring within cohorts and will place a greater focus on practices to overcome recognised learning barriers and to support students in making their learning more visible. 